\title{
Professor KC Nicolaou expanded the world of synthetic organic chemistry by total synthesis and his laboratories have fostered many talented researchers
}

\author{
The Journal of Antibiotics (2018) 71, 151-152; doi:10.1038/ja.2017.147
}

\begin{abstract}
$\mathrm{T}^{\mathrm{t}}$ is our great pleasure and honor to publish Professor KC Nicolaou special issue in The Journal of Antibiotics, focusing on the isolation of novel natural molecules and complex natural product total synthesis, bioorganic and medicinal chemistry, under the supervision of Editor-in-Chief, Professor Kuniaki Tatsuta, and with the cooperation of Guest Associate Editor, Professor Nicolas Winssinger. We sincerely appreciated the authors who not only submitted their original outstanding scientific articles and notes but also highly sophisticated review articles. As Professor Winssinger courteously introduced Professor Nicolaou's personal history and academic contributions in the preceding Editorial, I primarily would like to focus on how Professor Nicolaou dramatically changed the world of synthetic organic chemistry and total synthesis and the impact he has had on the past researchers from industry side in this Editorial.
\end{abstract}

As most of the organic chemistry journal readers recognize, Professor Nicolaou rapidly became globally well known as an independent researcher especially in the total synthesis community, via Columbia and Harvard University under supervision by Professor TJ Katz and Professor EJ Corey, respectively. In his first sacred place, The University of Pennsylvania, Professor Nicolaou generated a team with late Professor Ralph F Hirschmann and Professor Amos B Smith, III and co-authored several elegant medicinal chemistry papers ${ }^{1}$ based on the $\beta$-D-glucose scaffold. Many of the top managements in the big pharmaceutical industry focused on that seminal works, thus, early on, he got more attention from the populations who do not regularly follow total synthesis that much. And he succeeded in extending his playing field.

After Professor Nicolaou moved to San Diego (joint positions at The Scripps Research Institute in La Jolla and The University of California, San Diego), he has been one of luminaries worldwide, especially in the total synthesis field. At that time, the impact of synthetic organic chemistry dramatically changed, due to (i) the widespread application in chemical biology as well as (ii) the breakthrough in several combinatorial chemistry technologies. Several venture companies as well as pharmaceutical industry quickly jumped onto the latter and achieved several milestones. He initiated to adopt information and technology of chemical biology to his research concept and organized many chemical biology lectures at The Scripps Research Institute in La Jolla and The University of California, San Diego. One of them was delivered by Professor Stuart L Schreiber at Harvard University, three times in a row. These days, Professor
Nicolaou sent some outstanding $\mathrm{PhD}$ researchers to Professor Danishefsky's laboratories and these postdoctoral fellows practically contributed to accomplishments of some important total syntheses in Columbia University or Memorial Sloan-Kettering Cancer Center.

Professor Nicolaou not only managed several venture companies focusing on combinatorial chemistry in San Diego but also adopted concepts of chemical biology and combinatorial synthesis to his total synthesis of highly complex natural products. His paper ${ }^{2}$ entitled 'Chemical biology of epothilones' clearly indicated infinite spread of total synthesis of highly complex natural products to seed-identification and lead-identification or even candidate-identification by parallel synthetic methodology for pharmaceutical industries. As a result, the world of synthetic organic chemistry on total synthesis dramatically has been expanded by him.

In the second half of this Editorial, I would like to attach a few testaments from former researchers (visiting in the mid 90s) who recently recounted their experiences in his laboratories. Professor Nicolaou instilled cultural diversity as well as educated his coworkers in San Diego. (1) He has been always with us and supported us even after graduation with big heart. 'I can say he has always been there for support or recommendations whenever I've needed anything and I can't thank him enough for that. His labs also provided our company with some incredibly talented chemists over the years. Three of our four lead chemists came from his labs'. 'About our large project, we used to have a weekly meeting with him. Very often he gave us time to figure out the chemistry when met with unexpected results. Needless to say, when we made the final molecule, he was very elated and the manuscript was sent to the editor within a week! And over the years he has been very supportive of his former lab members. Whenever I approached him, always made time for me and sent the recommendation letter(s) within a working day. I truly am indebted to him'.

(2) He always has been kind and willing to cooperate to personal or industries. 'I stayed in his laboratory for only one month, but he was kind enough to introduce many reputed professors as well as provided meeting opportunities to me. Among them, meetings with late Professor Murray Goodman and Professor Stephen BH Kent were very impressive and the impact is still reverberating in my present research!' 'He kindly accepted consulting to our company for a couple of years. During that period, I often visited his office accompanied with our young chemists. Noteworthy, we initiated a few collaborations with US Pharma following his connections.' 'I really owe him for 
giving me an opportunity to work in his lab and meet and interact with several great chemists from all over the world. This was really important events in my life and I still keep in touch with several of those great friends'.

(3) He taught his coworkers the essence of chemistry and society. One of his former colleagues, now a reputed management, recollects Professor Nicolaou and quietly thinks that, 'Life is chemistry. The complexity starts outside the lab with people and the environment where we are the observers or the actors. The molecules we design every day are just a sample which we hope will help to contribute for a better tomorrow'.

From 28 May to 1 June 2006, International Symposium on Chemistry, Biology \& Medicine was held in Cyprus, Greece to celebrate Professor Nicolaou's 60th Birthday. The symposium was organized by Professor Nicos A. Petasis and colleagues, and $>300$ researchers attended from all over the world. From Japan, Professors Masakatsu Shibasaki and Jun'ichi Uenishi were the invited guest presenters. Almost all the attendees admitted that Professor Nicolaou can solve more complex scientific problems in future and has practically achieved many scientific breakthroughs. Professor Nicolaou must continue to have more influence not only to academia but also to pharmaceutical and material science industries.

For this special issue, worldwide topnotch chemists kindly submitted their deep content manuscripts under the direction of Professor Nicolas Winssinger. I would be pleased if our journal readers find some articles impressive and observe vast achievements and profound insights generated from KC community! At the closing of this Editorial, I would like to express sincere appreciation to Professor KC Nicolaou for his continuous supervision, and Dr Yoshio Hayashi (now professor), Dr Hari Khatuya, Dr James Leresche, Dr Andrew Patron, Dr K Paulvannan and Dr Hiroaki Ueno (alphabetical order) for their valuable remarks of their KC school from industry side. Devoted supports for this special issue by Mrs Yoko Takagi at Editorial Office are greatly appreciated.

\section{CONFLICT OF INTEREST}

The author declares no conflict of interest.

Keiichi Ajito

Department of Project Planning \& Management, Meiji Seika Pharma Co., Ltd., Tokyo, Japan E-mail:keiichi.ajito@meiji.com

1 Hirschmann, R. F., Nicolaou, K. C., Angeles, A. R., Chen, J. S. \& Smith, III, A. B. The $\beta$ D-glucose scaffold as a $\beta$-turn mimetic. Acc. Chem. Res. 42, 1511-1520 (2009).

2 Nicolaou, K. C., Roschangar, F. \& Vourloumis, D. Chemical biology of epothilones. Angew. Chem. Int. Ed. 37, 2014-2045 (1998). 